cation of abnormal aromatic compounds in the urine of a child with Reye like syndrome. Biomed Mass Spectrom 11:127-131

26. Chalmers RA, Lawson AM 1982 Organic Acids in Man. Chapman and Hall, New York

27. Bieber LL, Lewin LM 1981 Measurement of carnitine and O-acylcarnitines. Methods in Enzymology 72:282-286

28. Engel AG, Rebouche CJ 1984 Carnitine metabolism and inborn errors. J Inher Metab Dis 7(suppl 1):38-43

29. Roe CR, Millington DS, Maltby DA, Bohan TB, Hoppel CL 1984 L-Carnitine enhances excretion of propionyl-coA as propionylcarnitine in propionic acidemia. J Clin Invest 73:1785-1788

30. Roe CR, Hoppel CL, Stacey TE, Chalmers RA, Tracey RM, Millington DS 1983 Metabolic response to carnitine in methylmalonic aciduria: an effective strategy for elimination of propionyl groups. Arch Dis Child 58:916-920
31. Roe CR, Millington DS, Maltby DA, Kahler SG, Bohan TP 1984 L-Carnitine therapy in isovaleric acidemia. J Clin Invest 74:2290-2295.

32. Mamunes D, DeVries CH, Miller CD, David RB 1974 Fatty acid quantitation in Reye syndrome. In: Pollack JD (ed) Reye Syndrome. Grune and Stratton, New York, pp 245-254

33. Trauner DA, Adams H 1981 Intracranial pressure elevations during octanoate infusion in rabbits: An experimental model of Reye syndrome. Pediatr Res 15:1097-1099

34. Ogburn PL, Sharp H, Lloyd-Still JD, Johnson SB, Holman RT 1982 Abnormal polyunsaturated fatty acid patterns of serum lipids in Reye syndrome. Proc Natl Acad Sci USA 79:908-911

35. Kim CS, Dorgan DR, Roe CR 1984 L-Carnitine: therapeutic strategy for metabolic encephalopathy. Brain Res (in press)

\title{
Effects of Hypoxemia on Gastrointestinal Blood Flow and Gastric Emptying in the Newborn Piglet
}

\author{
JOANNE S. SZABO, BARBARA S. STONESTREET, AND WILLIAM OH \\ Department of Pediatrics, Women and Infants Hospital of Rhode Island, Providence 02908 and Brown University \\ Program in Medicine, Providence, Rhode Island 02912
}

\begin{abstract}
The effects of severe hypoxemia on gastrointestinal (GI) blood flow and gastric emptying were studied in nine 2- to 4-day-old piglets which were mechanically ventilated while receiving nitrous oxide anesthesia. Each animal was studied during a control period of oxygenation $\left(\mathrm{PaO}_{2} 91 \pm 8\right.$ torr), $35 \mathrm{~min}$ of hypoxemia $\left(\mathrm{PaO}_{2} 29 \pm 1\right.$ torr), and a recovery period $\left(\mathrm{PaO}_{2} 90 \pm 5\right.$ torr) (mean \pm $\mathrm{SEM})$. During each study period, the animal received a $10 \%$ dextrose test meal with phenol red marker $(22 \mathrm{ml} /$ $\mathrm{kg}$ ), gastric residual volumes were determined at $10-\mathrm{min}$ intervals over 30 -min study periods using a dye dilution double sampling technique, and GI blood flow (radionuclide-labeled microspheres), $\mathrm{O}_{2}$ delivery, $\mathrm{O}_{2}$ extraction, and $\mathrm{O}_{2}$ consumption were measured at the end of the 30min period. Hypoxemia resulted in decreased blood flow to the following GI organs: stomach, jejunal and ileal mucosa-submucosa, and colon decreased 62,31 , and $35 \%$, respectively $(p<0.05)$. Jejunal and ileal muscularis blood flow remained unchanged. Oxygen delivery and consumption by GI tract decreased 79 and $58 \%$, respectively; whereas oxygen extraction of GI tract increased $115 \%$. Values returned toward baseline levels during the recovery period. The hypoxemic gastric emptying pattern showed significantly greater gastric residuals at 20 min compared to the 10 -min value $(p<0.05)$. This pattern was different than that observed during control and recovery periods. We conclude that severe hypoxemia results in decreased GI blood flow, tissue oxygenation, and an altered gastric emptying pattern. These observations may have clinical significance for feeding infants following an hypoxemic episode. (Pediatr Res 19: 466-471, 1985)
\end{abstract}

Received July 9, 1984; accepted January 7, 1985.

Reprint requests to Dr. William Oh, 50 Maude Street, Providence, RI 02908.

Supported in part by Training Grant 1 T32HD07232-01 from the National Institute of Child Health and Human Development, Bethesda, MD.

\author{
Abbreviations \\ $\mathrm{CaO}_{2}$, arterial oxygen content \\ $\mathrm{CpvO}_{2}$, portal venous oxygen content \\ $\mathrm{DO}_{2} \mathrm{GI}$, oxygen delivery to gastrointestinal tract \\ $\mathrm{NO}_{2}$, nitrous oxide \\ $\mathrm{O}_{2}$ ExGI, oxygen extraction of the GI tract \\ OG, orogastric \\ $\dot{\mathrm{VO}} \mathrm{O}_{2} \mathrm{GI}$, oxygen consumption by GI tract \\ GI, gastrointestinal
}

Hypoxemia places the neonate at risk for developing GI complications. Among those suggested by clinical studies are necrotizing enterocolitis as a result of perinatal asphyxia and decreased GI blood flow (1), and decreased gastric emptying resulting from respiratory distress syndrome and congenital cyanotic heart disease $(2,3)$.

The effect of hypoxemia on GI blood flow appears to vary depending on the degree of hypoxemia and perhaps the age of the subject. Moderate hypoxemia causes intestinal hyperemia in adult animals as a means of maintaining constant $\mathrm{O}_{2}$ delivery and consumption to the GI tract $(4,5)$. Severe hypoxemia in fetal and newborn ruminant animals results, instead, in significant increases in $\mathrm{O}_{2}$ extraction as an attempt to maintain $\mathrm{GI} \mathrm{O}_{2}$ consumption $(6,7)$. The compensatory response utilized by hypoxemic, nonruminant newborn animals to maintain adequate GI tissue oxygenation has not been previously defined.

Hypoxemia and ischemia alter the viability of GI motor function (8). Previous studies in adult animals show an association between GI blood flow and motility (9-13). These studies suggest that changes in blood flow may produce alterations in motility and vice versa. Such an association would be important to verify in the newborn since altered gastrointestinal motility may ac- 
count for many of the clinical features of feeding intolerance in hypoxemic and formerly hypoxemic infants.

This study examined the effects of hypoxemia on GI blood flow and oxygen transport in the newborn piglet, as well as the effect on one aspect of GI motility-the gastric emptying pattern.

\section{MATERIALS AND METHODS}

Animal preparation. Nine 2- to 4-day-old piglets with a mean weight of $1.11 \mathrm{~kg}$ (range $0.85-1.45 \mathrm{~kg}$ ) were studied. Animals were obtained from a local breeder $24 \mathrm{~h}$ prior to the study and received ad libitum feedings by mouth of $10 \%$ dextrose in order to reduce milk curd residual and facilitate gastric emptying studies. On the morning of the study, animals were weighed, restrained supine, and maintained normothermic on an infant radiant warmer. They received nitrous oxide $(40 \%)$ and local (1\% lidocaine) anesthesia for surgical placement of catheters which included: 1) a left ventricular catheter (via left common carotid artery) for microsphere injections, 2) a portal venous catheter (via common umbilical vein) for venous oxygen content, 3) a distal aorta catheter (via femoral artery) for arterial oxygen content, arterial blood gas samples, and reference blood sample withdrawal during microsphere injections, 4) a femoral artery catheter for continuous heart rate and blood pressure monitoring, and 5) a femoral or jugular venous catheter for blood replacement. In preliminary studies, gastric emptying was initially attempted in awake, unanesthetized newborn piglets. Because of excitability during manipulative procedures (OG tube placement) and difficulty in interpreting gastric emptying patterns, animals were tracheotomized and mechanically ventilated with a volume ventilator (Harvard Apparatus, Millis, MA, Rodent Respirator, model 681) at a stroke volume of $10 \mathrm{ml} / \mathrm{kg}$ with a rate of approximately $40 / \mathrm{min}$ to maintain the $\mathrm{PaCO}_{2} 27-49$ torr. Animals remained under $\mathrm{NO}_{2}$ anesthesia throughout the remainder of the study. An 8-French polyethylene feeding catheter was passed orally into the stomach, measured, and secured with the tip approximately $2.5 \mathrm{~cm}$. below the xyphoid process. This catheter placement resulted in an intragastric position above the pyloric antrum on all autopsy examinations. The stomach contents were aspirated through the $O G$ tube and the stomach was washed with approximately $100 \mathrm{ml} \mathrm{H}_{2} \mathrm{O}$ to ensure that it was empty of food and bile. The animal was allowed a 60 -min equilibration period prior to beginning the study.

Experimental protocol. Each animal was studied during control, hypoxemic, and recovery periods. Under control conditions, gastric emptying was determined at 10 -min intervals over a $30-$ min sampling period. An arterial blood gas and arterial and portal venous samples were drawn for oxygen content determinations, and an injection of radionuclide-labeled microspheres was given to determine GI blood flow. At 85 min following this determination, the animal was rendered hypoxemic with a mixture of $10 \% \mathrm{O}_{2}, 5 \% \mathrm{CO}_{2}$, balanced $\mathrm{N}_{2}$ added through a $\mathrm{Y}$ connector to the ventilator. Arterial blood gases were obtained at 5-min intervals for $15 \mathrm{~min}$ until the $\mathrm{PaO}_{2}$ was stable at approximately 30 torr. The animal remained hypoxemic, was given a test meal, and had gastric emptying pattern, blood gases, oxygen contents, and GI blood flow determined in the same manner as in the control period. At the end of this study period, the ventilator gas mixture was returned to prehypoxemic levels. The animal was allowed to recover for $70 \mathrm{~min}$, when the above determinations were repeated. Hematocrits were followed on arterial blood samples using a microcapillary technique. Plasma glucose values were determined using a glucose analyzer (YSI model 23A, Fisher Scientific Co., Yellow Springs, OH). Arterial blood gas measurements were made using a Corning 175 Blood Gas Analyzer (Corning Scientific, Medford, MA). Oxygen contents were determined in duplicate using a Lex- $\mathrm{O}_{2}$-Con (Lexington Instruments, Waltham, MA). At the conclusion of the study the animal was given a lethal injection of sodium thiamylal.
Blood flow and oxygen transport determinations. Blood flow determinations were made using the radionuclide-labeled microsphere technique (14-16). Microspheres, $15 \pm 5 \mu$ in diameter, were labeled with one of six radionuclides: ${ }^{46} \mathrm{Sc},{ }^{51} \mathrm{Cr},{ }^{57} \mathrm{Co},{ }^{95} \mathrm{Nb}$, ${ }^{103} \mathrm{Ru}$, and ${ }^{113} \mathrm{Sn}$ (New England Nuclear Inc., Boston, MA). Approximately $6 \times 10^{5}$ microspheres, suspended in a $10 \%$ Dextran solution with $0.01 \%$ Tween 80 were continuously agitated and injected into the left ventricular catheter for $30 \mathrm{~s}$, the catheter was flushed with $2.0 \mathrm{ml}$ of $0.9 \% \mathrm{NaCl}$, and a reference blood sample was withdrawn from the femoral artery catheter at a rate of $1.03 \mathrm{ml} / \mathrm{min}$ beginning $10 \mathrm{~s}$ before microsphere injection and lasting for $120 \mathrm{~s}$. Heart rate and blood pressure were monitored throughout the study using a Hewlett-Packard transducer and polygraph recorder (7754 A series, Lexington, MA), and remained stable throughout each period of microsphere injection and blood withdrawal. The animal was transfused with an equal volume of young donor pig blood of similar hematocrit, following each microsphere sample, in order to maintain the hematocrit at control values.

At autopsy, catheter placement was verified. The stomach, small intestine, and colon were removed, washed gently in normal saline, weighed, and fixed in $10 \%$ formaldehyde for a minimum of $48 \mathrm{~h}$. The small intestine was divided into proximal (jejunum) and distal (ileum) sections and further separated into submucosa-mucosa and muscularis-serosa segments using a blunt dissection technique $(15,17)$. Previous studies have shown that microspheres $15 \pm 5 \mu$ do not accurately distinguish submucosal and mucosal flow because of series arrangement of these circulations. By fractionating the intramural flow into the parallel circulations of mucosa-submucosa and muscularis-serosa, this problem, as well as migration of previously lodged spheres, is overcome since migration would occur only within series circulations $(15,18)$. Tissue samples were packed to approximately 1 $\mathrm{cm}$ in height in plastic counting vials. Blood and tissue specimens were counted in a well-type gamma scintillation spectrometer (Packard Auto-gamma Scintillation Spectrometer, Packard Instruments, Downes Grove, IL). All samples were corrected for isotope decay and spillover counts using a Digital PdP-11/34 computer (Digital Equipment, Maynard, MA). In all cases, more than 400 microspheres were present in the tissue and reference blood samples to ensure accuracy of blood flow determinations to within $5-10 \%(16)$.

GI tissue blood flow was determined by the following equation: GI tissue blood flow $=\mathrm{cpm}$ GI tissue $/ \mathrm{cpm}$ reference $\times$ rate of reference blood withdrawal.

Total GI blood flow and regional blood flows were determined by summation of the appropriate tissue samples. $\mathrm{DO}_{2}, \dot{\mathrm{VO}} \mathrm{O}_{2}$, and $\dot{\mathrm{V}} \mathrm{O}_{2} / \mathrm{DO}_{2}$ were calculated using the following formulas derived from the Fick principle:

$$
\begin{aligned}
\mathrm{DO}_{2} & =\dot{\mathrm{Q}} \times \mathrm{CaO}_{2} \\
\dot{\mathrm{VO}}_{2} & =\dot{\mathrm{Q}} \times\left(\mathrm{CaO}_{2}-\mathrm{CpvO}_{2}\right) \\
\dot{\mathrm{VO}}_{2} / \mathrm{DO}_{2} & =\left(\mathrm{CaO}_{2}-\mathrm{CpvO}_{2}\right) / \mathrm{CaO}_{2}
\end{aligned}
$$

where $\mathrm{Q}$ is blood flow, $\mathrm{CaO}_{2}$ is arterial oxygen content, and $\mathrm{CpvO}_{2}$ is portal venous oxygen content. The validity of $\mathrm{CpvO}_{2}$ to represent $\mathrm{GI}$ venous samples has been confirmed previously $(7,17)$. Blood flow was expressed as $\mathrm{ml} \cdot \mathrm{min}^{-1} \cdot 100 \mathrm{~g}^{-1}$ and $\mathrm{DO}_{2}$ and $\mathrm{VO}_{2}$ were expressed as $\mathrm{ml} \mathrm{O}_{2} \cdot \min ^{-1} \cdot 100 \mathrm{~g}^{-1}$.

Gastric emptying determination. Gastric emptying was determined at 10 -min intervals for a total of 30 min using a phenol red dye dilution double sampling technique $(19,20)$. Approximately 60 min prior to the gastric emptying determinations, the stomach was aspirated of all contents, washed until the aspirate was clear and free of milk curds, then completely emptied. At the time of each study, the animal was given $22 \mathrm{ml} / \mathrm{kg}$ test meal by $\mathrm{OG}$ tube. The test meal consisted of $10 \%$ dextrose in water with $60 \mathrm{mg} / \mathrm{liter}$ phenol red (Sigma Chemical Co., St. Louis, 
MO) adjusted to $\mathrm{pH} 7.0$ using $1.0 \mathrm{~N} \mathrm{NaOH}$. The feeding was administered at room temperature $\left(\sim 25^{\circ} \mathrm{C}\right)$ and allowed to drip in by gravity for $2 \mathrm{~min}$ (range $1-3 \mathrm{~min}$ ). At $10 \mathrm{~min}$ after completion of the feeding, $2.5 \mathrm{ml}$ of gastric content were removed, $5 \mathrm{ml}$ of stock solution (phenol red $250 \mathrm{mg} /$ liter $\mathrm{H}_{2} \mathrm{O}$ ) were added through the OG tube and mixed (45 sec in $5-\mathrm{ml}$ aliquots), and a second $2.5-\mathrm{ml}$ sample of gastric contents was removed $(2.5 \mathrm{ml}$ was the minimum volume needed to assay samples in duplicate). This resulted in no net change in volume due to sampling. For the study done at $20 \mathrm{~min}$ following feeding, $2.5 \mathrm{ml}$ of stock solution were added, and at $30 \mathrm{~min} 1.0 \mathrm{ml}$ of stock solution was added. The volume of the added stock solution was reduced during the 20 - and 30 -min periods to take into account the smaller gastric volumes during these study periods (20). This resulted in a small loss of volume due to sampling, which should not have interfered with the gastric emptying pattern (21).

Gastric samples were centrifuged to remove mucous and debris, then diluted 1:24 with $0.02 \mathrm{M}$ trisodium orthophosphate buffer (Sigma Chemical Co.). The absorbance of this mixture was determined in duplicate using a Gilford 240 spectrophotometer at $560 \mathrm{~m} \mu$, and the concentration of samples was determined from a standard curve. By determining the concentration of gastric residuals before and after the addition of a known volume and concentration of stock solution, gastric residual volume at the end of each 10 -min test interval could be calculated from the following equation:

$$
\mathrm{Vt}=\frac{\mathrm{V}_{2}\left(\mathrm{C}_{2}-\mathrm{C}_{3}\right)}{\mathrm{C}_{3}-\mathrm{C}_{1}}+\mathrm{V}_{1}
$$

$\mathrm{Vt}=$ gastric residual volume at each time period; $\mathrm{C}_{1}=$ phenol red concentration of initial gastric residual; $V_{2}=$ volume of added stock solution; $\mathrm{C}_{2}=$ phenol red concentration of added stock solution; $C_{3}=$ phenol red concentration of final gastric

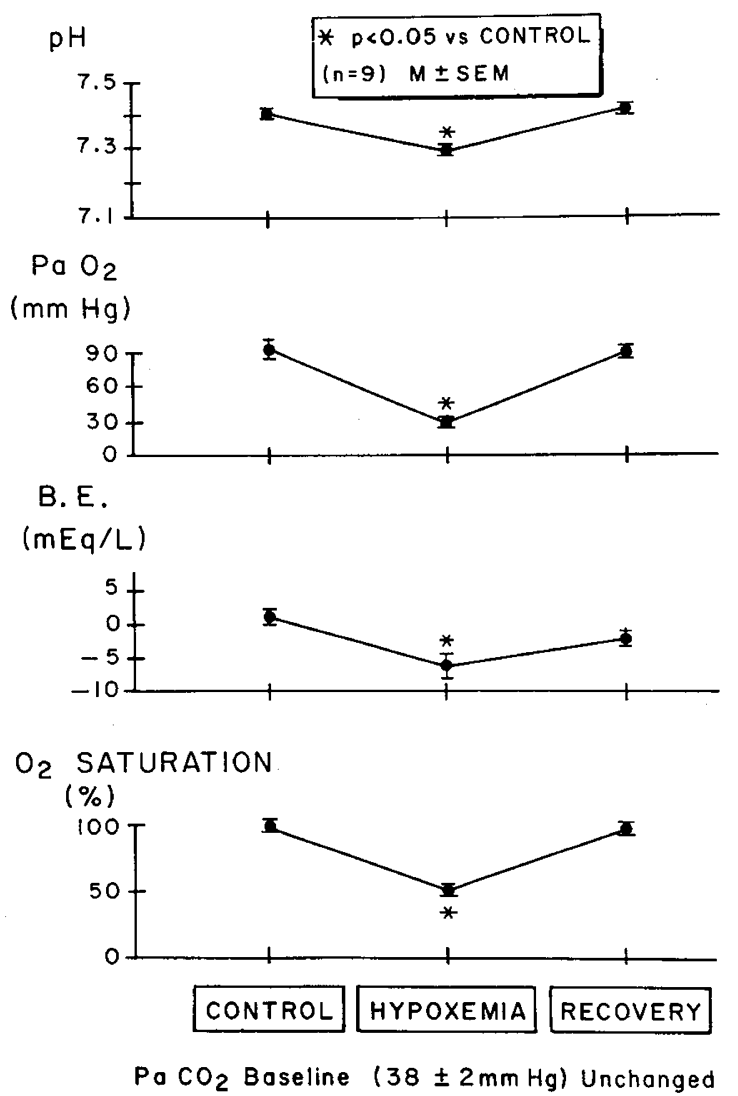

Fig. 1. Arterial blood gas values during control, hypoxemic, and recovery periods.
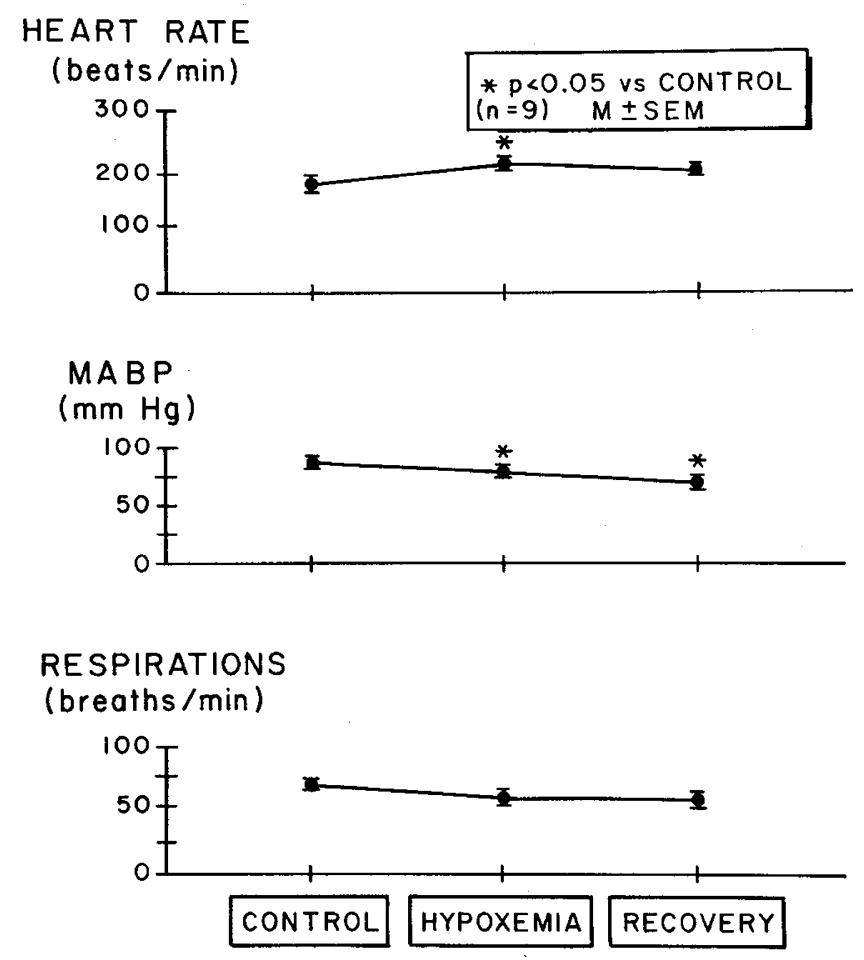

Fig. 2. Heart rate, mean arterial blood pressure, and respiratory rate during the three study periods.

residual; $\mathrm{V}_{1}=$ volume removed for sampling initial gastric residual. Because all volumes added and removed for sampling purposes were precisely measured, the small net loss of volume was added to the calculated gastric residual volume where appropriate.

Simulated in vitro gastric emptying studies were performed to test the validity of our technique. At each time period we determined the measured percentage total volume of test meal, the estimated percentage total volume of test meal, and the measured versus experimentally estimated volume (error percentage total volume). In conditions simulating the 10 -min sampling period, the mean error estimation was $5.5 \pm 2.7 \%, 20$-min mean error estimation was $10.6 \pm 2.4 \%$, and 30 -min mean error estimation was $10.8 \pm 4.4 \%$ (mean \pm SEM).

\section{DATA ANALYSIS}

Data analysis was performed using a blocked one-way analysis of variance for repetitive measures to detect statistical significance. If a significant difference was found $(p<0.05)$, the Dunnett's multiple range $T$ test was used to compare the means. Values were expressed as mean \pm SEM.

\section{RESULTS}

The arterial blood gas values during the three study periods are shown in Figure 1. During hypoxemia, $\mathrm{pH}, \mathrm{PaO}_{2}$, base excess, and oxygen saturation were significantly reduced compared to control and recovery values $(p<0.05)$. The animals were mechanically ventilated with stable $\mathrm{PaCO}_{2}$, and the acidosis occurred on a metabolic basis. These variables corrected spontaneously to baseline during the recovery period. As shown in Figure 2, heart rate and mean arterial blood pressure changed significantly from baseline values during hypoxemia. Heart rate increased by $21 \%$ over baseline values during hypoxemia, and returned toward baseline during recovery. Although mean arterial blood pressure decreased significantly from baseline during the hypoxemic and recovery periods $(p<0.05)$, at no time did the blood pressure fall into the hypotensive range (study range 
56-96 $\mathrm{mm} \mathrm{Hg}$ ). The respiratory rates did not increase with hypoxemia because animals were mechanically ventilated at 61 \pm 6 breaths $/ \mathrm{min}$. During the control period, serum glucose values were $92 \pm 10 \mathrm{mg} / \mathrm{dl}$ and hematocrits were $31 \pm 2 \%$, and these values did not change significantly during the three study periods.

Figure 3 depicts total GI blood flow changes, arterial oxygen contents, and arterial-venous oxygen content differences across the GI tract during the three study periods. Total GI blood flow decreased significantly by $34 \%$ during hypoxemia $(p<0.05)$. $\mathrm{CaO}_{2}$ in our animals during the hypoxemic period ranged from $2.8-6.3 \mathrm{ml} / \mathrm{dl}$ with a mean of $4.4 \pm 0.5 \mathrm{ml} / \mathrm{dl}$. Because of similar decreases in arterial and portal venous oxygen contents, the arteriovenous difference remained essentially unchanged. The reduction in GI blood flow resulted from significant reductions in regional blood flow to the stomach, small intestinal mucosa, and colon (Fig 4). Stomach blood flow decreased $62 \%$ during hypoxemia as compared to baseline and recovery values $(p<$ $0.05)$. Total small intestine blood flow decreased significantly ( $p$ $<0.05$ ), with jejunal and ileal mucosa flow decreased by 30 and $33 \%\left(210 \pm 34\right.$ to $148 \pm 35$ and $147 \pm 19$ to $99 \pm 23 \mathrm{ml} \cdot \mathrm{min}^{-1}$. $\left.100 \mathrm{~g}^{-1}\right)$, respectively. Jejunal mucosa flow was lower during recovery than during the baseline period. Muscularis blood flow remained unchanged except for the jejunum which showed an increase in flow by $59 \%$ above baseline during the recovery period $\left(44 \pm 4\right.$ to $\left.70 \pm 11 \mathrm{ml} \cdot \mathrm{min}^{-1} \cdot 100 \mathrm{~g}^{-1}\right)$. Colon blood flow decreased by $35 \%$ during the hypoxemic period and returned toward baseline during the recovery period.

Figure 5 illustrates changes in $\mathrm{DO}_{2} \mathrm{GI}, \mathrm{O}_{2} \mathrm{ExGI}$, and $\mathrm{VO}_{2} \mathrm{GI}$ resulting from hypoxemia. $\mathrm{DO}_{2}$ GI decreased $79 \%, \mathrm{O}_{2}$ ExGI increased $115 \%$ in order to compensate for decreased tissue oxygenation; nevertheless oxygen consumption was reduced by $58 \%(p<0.05) . \mathrm{DO}_{2} \mathrm{GI}$ and $\mathrm{O}_{2}$ ExGI returned toward baseline during the recovery period; however, $\dot{\mathrm{VO}}_{2} \mathrm{GI}$ remained lower than baseline values.

The gastric residual volumes, expressed as $\mathrm{ml} / \mathrm{kg}$ body weight of the nine piglets, are shown in Figure 6 . The gastric residual

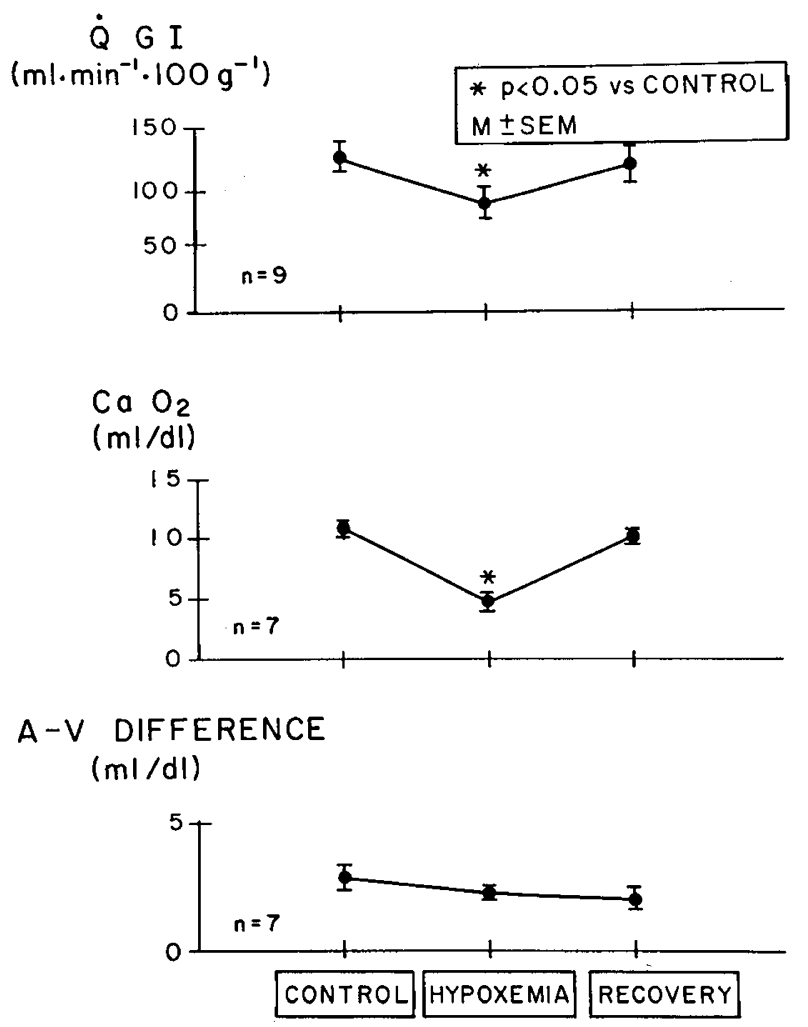

Fig. 3. Total gastrointestinal blood flow, arterial oxygen content, and arterial-venous oxygen difference during the three study periods.
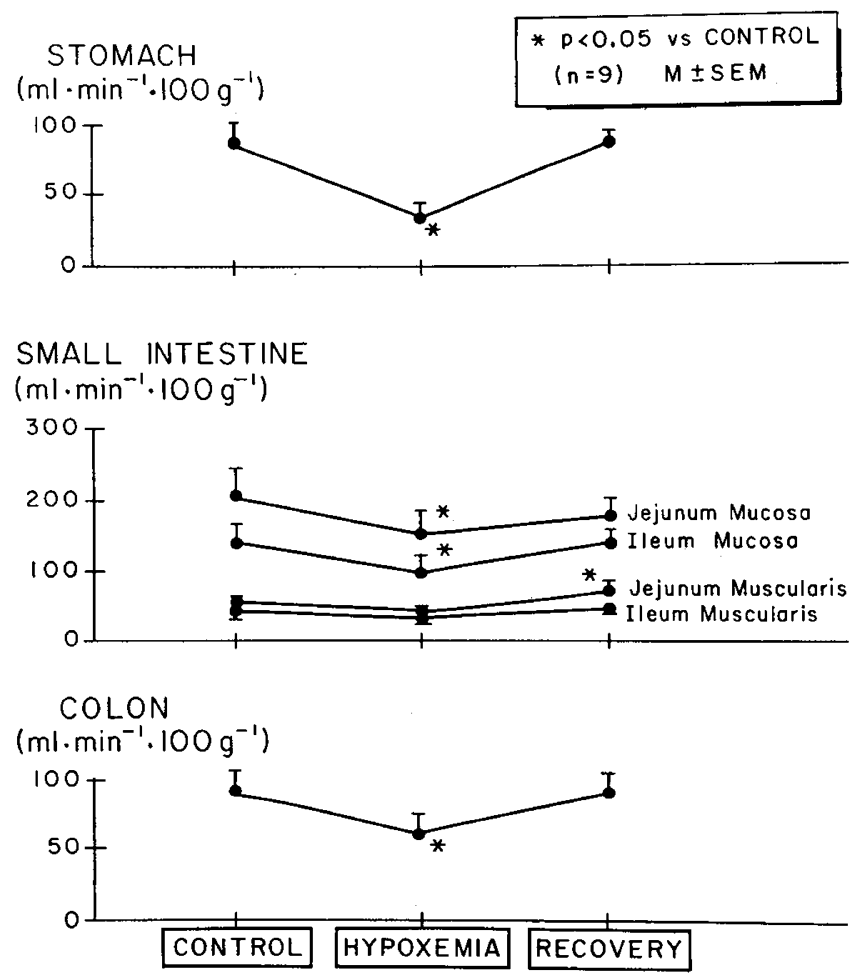

Fig. 4. Regional GI blood flow during control, hypoxemic, and recovery periods.
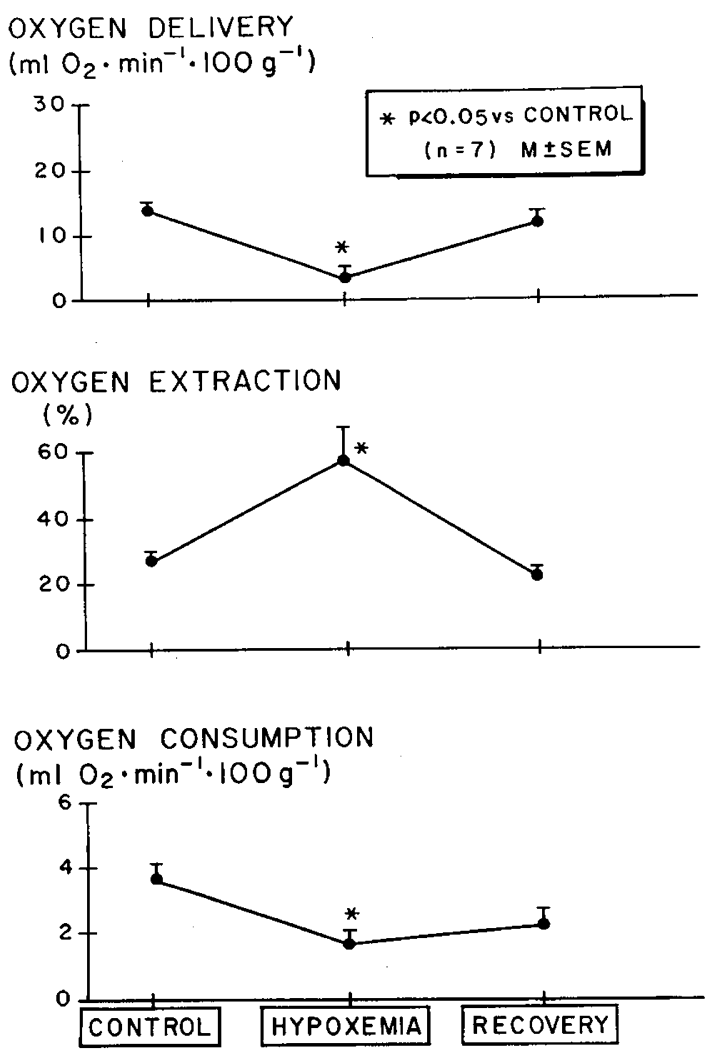

Fig. 5. $\mathrm{DO}_{2} \mathrm{GI}, \mathrm{O}_{2} \mathrm{ExGI}$, and $\mathrm{VO}_{2} \mathrm{GI}$ during the three study periods.

volumes (mean \pm SEM) during the control period at 10,20 , and $30 \mathrm{~min}$ were $22.9 \pm 3.1,24.7 \pm 2.5$, and $19.8 \pm 2.6$, respectively. During hypoxemia, the 20 -min residual was significantly higher $(p<0.05)$ than the 10 -min residual $(30.8 \pm 6.1$ versus $21.3 \pm$ 2.8 , respectively). Recovery values at 10,20 , and $30 \mathrm{~min}$ were 


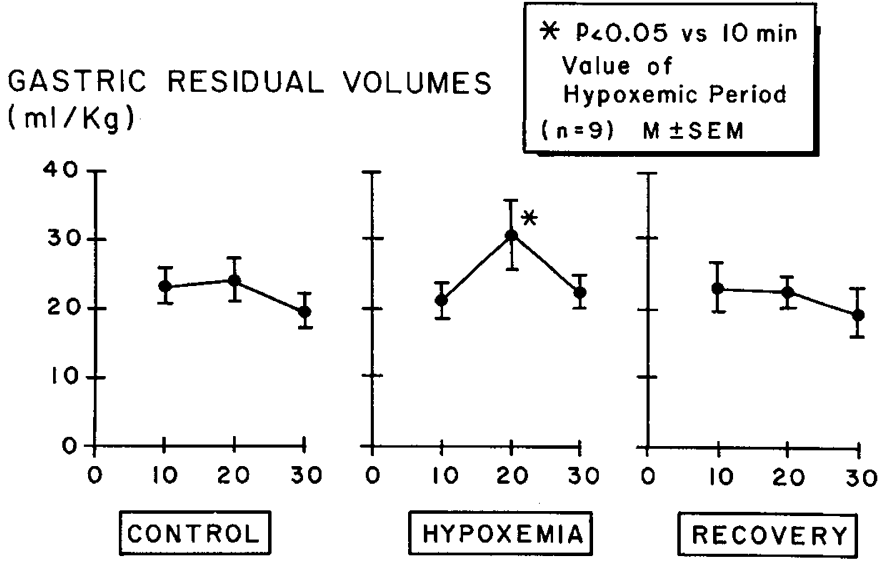

TIME (Minutes)

Fig. 6. Gastric emptying patterns during control, hypoxemic, and recovery periods.

not significantly different from control. When comparisons were made at 10,20, and 30 min among the three study periods, no significant differences were found.

\section{DISCUSSION}

Our piglets were studied under nitrous oxide anesthesia in order to facilitate the gastric emptying studies. $\mathrm{NO}_{2}$ has no effect in newborn piglets on arterial $\mathrm{pH}, \mathrm{PaO}_{2}, \mathrm{PaCO}_{2}$, heart rate, mean arterial blood pressure, respiratory rate, or hematocrit; however, it may result in significant increases in total peripheral resistance and decreases in cardiac output when compared to control values (22). Since our animals received constant amounts of $\mathrm{NO}_{2}$ throughout the study and hypoxemic values returned to baseline during the recovery period, anesthesia probably did not contribute to differences observed during the three study periods.

The effects of severe hypoxemia $\left(\mathrm{PaO}_{2} 29 \pm 1\right.$ torr) on the newborn piglet were studied. These levels were chosen to be similar to other newborn studies (6) and to reflect levels that infants might acutely experience during asphyxia, respiratory distress, or severe apnea. The metabolic acidosis resulting from anaerobic metabolism at this low level of oxygenation was unavoidable; however the degree and severity of hypoxemia was not sufficient to cause permanent damage, as evidenced by the return of most study variables toward baseline during the recovery period. The vasodilatory effects of hypercapnea (5) were controlled by providing ventilatory support at a level sufficient to maintain $\mathrm{PaCO}_{2}$ within the normal range.

The baseline heart rates of our study animals were comparable to those recorded by others $(17,23)$. Our respiratory rates were higher than those seen in awake, unanesthetized animals; however baseline blood gas variables were comparable. Baseline mean arterial blood pressure values in our restrained anesthetized animals were higher than control values in awake, unanesthetized piglets $(17,23)$ but similar to those in restrained animals $(24$, 25 ). The decrease in blood pressure toward normal values during the study may have resulted from adaptation to the study environment. Because mean arterial blood pressures remained within normal limits in all animals, the decreases noted would, in all likelihood, not have resulted in decreased perfusion pressures.

Our baseline values of 30-min postprandial GI blood flow, oxygen delivery, extraction, and consumption were similar to previously reported studies in awake, unanesthetized piglets (17), except for slightly lower stomach blood flows which may have reflected differences in the type of feeding. Studies in adult dogs have shown that moderate hypoxemia results in marked increases in intestinal blood flow to maintain $\mathrm{O}_{2}$ delivery and consumption (4). We have shown that severe hypoxemia in the newborn piglet causes significant decreases in stomach, small intestinal mucosa, and colon blood flow, as well as decreases in oxygen delivery and consumption. These results are consistent with those seen in the ovine fetus (7). These changes most likely reflect the compensatory routing of cardiac output to high priority organs (brain and heart) in the presence of hypoxemia, at the expense of low priority organs such as the GI tract $(26,27)$. We could not calculate oxygen consumption of the stomach directly because of lack of gastric venous oxygen content data, but it is likely that gastric tissue oxygenation was reduced similarly to the total GI tract.

Most of the parameters that we measured returned to baseline values during the recovery period. Oxygen consumption increased, but remained below baseline values $(2.2 \pm 0.4$ versus $3.6 \pm 0.5 \mathrm{ml} \mathrm{O} \cdot \mathrm{min}^{-1} \cdot 100 \mathrm{~g}^{-1}$ ). Edelstone reported similar results in fetal lambs with $\mathrm{CaO}_{2} \leq 4.4 \mathrm{ml} / \mathrm{dl}$ (7). In four of seven of our animals, we noted a failure to meet oxidative demands when $\mathrm{O}_{2}$ delivery decreased below a critical level $(<20 \%$ of baseline values) or $\mathrm{O}_{2}$ extraction did not sufficiently increase (to $\geq 63 \%$ above baseline values).

The composition of a meal affects gastric emptying and intestinal hyperemia (28-31). The $10 \%$ dextrose test meal minimized such variables as fat, amino acid content, and physical composition, yet provided sufficient caloric content (32-34) to slow gastric emptying enough to allow us to detect differences among study periods. This test meal has an osmolality of $\sim 615 \mathrm{mOsmol} /$ $\mathrm{kg}$. Hyperosmolar feedings lead to greater stimulation of endogenous secretions, intraluminal water diffusion (35), and mucosal damage (36). However, osmolalities $\leq 448 \mathrm{mOsmol} / \mathrm{kg}$ have not been associated with significant changes in gastric emptying (37), and $\leq 1000 \mathrm{mOsmol} / \mathrm{kg}$ have not been associated with intestinal hyperemia (38). Changes produced with a dextrose meal may not be reflective of the response to a milk feeding $(17,39)$, since unanesthetized hypoxemic piglets given a milk feeding demonstrate a greater ability to maintain $\mathrm{GI} \mathrm{O}_{2}$ consumption (40).

Motor, neural, and hormonal factors interact to regulate gastric emptying. Ischemia may alter the mechanical and electrical activity of the GI tract (8), resulting in decreased motility and the increased gastric residuals we observed at $20 \mathrm{~min}$; however with such a mechanism we would expect residuals to remain unchanged or be increased at $30 \mathrm{~min}$. Sympathetic nervous discharge in response to hypoxemia suppresses gut activity (41), and neural factors may act directly or in conjunction with motor influences. GI hormonal response to hypoxemia remains to be explored; perhaps hypoxemia alters the duodenal receptor responses regulating gastric emptying.

Increased saliva and gastric secretions could account for the greater than expected dilution of phenol red in those instances of increased gastric residuals at $20 \mathrm{~min}$ (five of nine animals). However, we would expect secretory response to be impaired in view of sympathetic stimulation and the significantly decreased stomach blood flow (9). Another more likely explanation for increased residuals relates to increased gastric emptying resistance or duodenal reflux. Ischemia leads to a pattern of sustained tonic intestinal contractions with active hyperemia in the intestinal muscularis (11). The absence of jejunal and ileal muscularis ischemia during hypoxemia and presence of jejunal muscularis hyperemia during recovery suggest intestinal motility may be increased, at least transiently, during hypoxemia. Bean and Sidky (42) observed that hypoxemia-induced tone and motility depression was preceded by a brief stimulation. Such transient increases in tone could account for duodenogastric reflux and the increased gastric residual volumes observed at the 20 -min period during hypoxemia.

We have demonstrated that severe hypoxemia in the newborn piglet leads to reduced GI tract blood flow in the stomach, small intestinal mucosa-submucosa, and colon following a $10 \%$ dextrose meal. Blood flow to the mucosa-submucosa is more significantly reduced than flow to the muscularis as a result of preferential arteriolar shunting of blood away from the mucosa-sub- 
mucosa, with sparing of flow to the muscularis layer (27). This may reflect less intrinsic protection of the mucosa-submucosa against the damaging effects of ischemia. In cases of reduced blood flow and $\mathrm{O}_{2}$ delivery, the fetal and newborn intestinal tract is capable of increasing $\mathrm{O}_{2} \mathrm{ExGI}$ in order to maintain stable oxygen consumption $(6,7)$. It appears that at critically low levels of $\mathrm{O}_{2}$, this compensatory mechanism is impaired or insufficient and $\mathrm{VO}_{2} \mathrm{GI}$ is reduced.

Concomitant with these hypoxemic-induced blood flow and oxygen transport changes an altered gastric emptying pattern is noted. The increased gastric residual volumes that we noted at the 20 -min period of hypoxemia were probably produced by transient increases in intestinal tonicity with resultant increased gastric emptying resistance or duodenogastric reflux. The transient nature of this phenomenon would suggest that increased intestinal tone or motility was not responsible for the decreased blood flow we observed during hypoxemia.

These observations may have clinical significance for feeding infants following a hypoxemic episode. GI blood flow reduction appears to resolve rapidly following transient hypoxemia; however recovery is less in the jejunal mucosa. Oxygen consumption is impaired at critically low levels of oxygen despite the ability to increase oxygen extraction, and appears to be one of the last variables to recover following a hypoxemic insult. Altered gastric emptying patterns during hypoxemia may or may not be related to blood flow changes and, after limited periods of hypoxemia, appear transient in nature.

Acknowledgments. The authors acknowledge the technical assistance of Mr. Steven Warburton and Ms. Carol Calista, and the cooperation of Dr. Albert Most, FACC and the staff of the Rhode Island Hospital Cardiovascular Research Laboratory.

\section{REFERENCES}

1. Kliegman RM, Hack M, Jones P, Fanaroff AA 1982 Epidemiologic study of necrotizing enterocolitis among low-birth-weight infants. J Pediatr 100:440444

2. Yu VYH 1975 Effect of body position on gastric emptying in the neonate. Arch Dis Child 50:500-504

3. Cavell B 1981 Gastric emptying in infants with congenital heart disease. Acta Paediatr Scand 70:517-520

4. Shepherd AP 1978. Intestinal $\mathrm{O}_{2}$ consumption and ${ }^{86} \mathrm{Rb}$ extraction during arterial hypoxia. Am J Physiol 234:E248-E25

5. Svanvik J, Tyllstrom J, Wallentin I 1968 The effects of hypercapnia and hypoxia on distribution of capillary blood flow in the denervated intestinal vascular bed. Acta Physiol Scand 74:543-551

6. Nowicki PT, Hansen NB, Oh W, Stonestreet B 1984 Gastrointestinal blood flow and oxygen consumption in the newborn lamb: effect of chronic anemia and acute hypoxia. Pediatr Res 18:420-425

7. Edelstone DI, Holzman IR 1982 Fetal intestinal oxygen consumption at various levels of oxygenation. Am J Physiol 242:H50-H54

8. Kowalewski K, Zajac S, Kolodej A 1976 Effect of ischemic anoxia on electrical and mechanical activity of the totally isolated porcine stomach. Eur Surg Res 8:12-25

9. Bynum TE, Jacobson ED 1971 Blood flow and gastrointestinal function. Gastroenterology 60:325-335

10. Chou CC 1982 Relationship between intestinal blood flow and motility. Ann Rev Physiol 44:29-42

11. Chou CC, Grassmick B 1978 Motility and blood flow distribution within the wall of the gastrointestinal tract. Am J Physiol 235:H34-H39

12. Jacobson ED, Brobmann GF, Brecher GA 1970 Intestinal motor activity and blood flow. Gastroenterology 58:575-579

13. Walus KM, Jacobson ED 1981 Relation between small intestinal motility and circulation. Am J Physiol 241:G1-G15

14. Archibald LH, Moody FG, Simons M 1975 Measurement of gastric blood flow with radioactive microspheres. J Appl Physiol 6:1051-1056

15. Bond JH, Levitt MD 1979 Use of microspheres to measure small intestinal villus blood flow in the dog. Am J Physiol 236:E577-E583

16. Heymann MA, Payne BD, Hoffman JIE, Rudolph AM 1977 Blood flow measurements with radionuclide-labeled particles. Prog Cardiovasc Dis 20:55-79

17. Nowicki PT, Stonestreet BS, Hansen NB, Yao AC, Oh W 1983 Gastrointestinal blood flow and oxygen consumption in awake newborn piglets: effect of feeding. Am J Physiol 245:G697-G702

18. Maxwell L, Shepherd A, Riedel G, Morris M 1981 Effect of microsphere size on apparent intramural distribution of intestinal blood flow. Am J Physiol 241:H408-H414

19. Cavell B 1979 Gastric emptying in preterm infants. Acta Paediatr Scand 68:725-730

20. George JD 1968 New clinical method for measuring the rate of gastric emptying: the double sampling test meal. Gut 9:237-242

21. Cooke AR 1975 Control of gastric emptying and motility. Gastroenterology 68:804-816

22. Bailie MD, Alward CT, Sawyer DC, Hook JB 1979 Effect of anesthesia on cardiovascular and renal function in the newborn piglet. J Pharm Exp Ther 208:298-302

23. DeRoth L, Downie HG 1978 Basic cardiovascular parameters in the underweight neonatal swine. Biol Neonate 34:155-160

24. Laptook A, Stonestreet BS, Oh W 1982 The effects of different rates of plasmanate infusions upon brain blood flow after asphyxia and hypotension in newborn piglets. J Pediatr 100:791-796

25. Stephens DB, Rader RD 1983 Effects of vibration, noise and restraint on heart rate, blood pressure and renal blood flow in the pig. $J$ R Soc Med 76:841847

26. Stonestreet BS, Laptook A, Schanler R, Oh W 1982 Hemodynamic responses to asphyxia in spontaneously breathing newborn term and premature lambs. Early Hum Dev 7:81-97

27. Touloukian RJ, Posch JN, Spencer R 1972 The pathogenesis of ischemic gastroenterocolitis of the neonate: selective gut mucosal ischemia in asphyxiated neonatal piglets. J Pediatr Surg 7:194-205

28. Hunt JN, Knox MT 1968 A relation between the chain length of fatty acids and the slowing of gastric emptying. J Physiol 194:327-336.

29. Cooke AR, Moulang J 1972 Control of gastric emptying by amino acids. Gastroenterology 62:528-532

30. Kelly KA 1980 Gastric emptying of liquids and solids: role of proximal and distal stomach. Am J Physiol 239:G71-G76

31. Siregar H, Chou CC 1982 Relative contribution of fat, protein, carbohydrate, and ethanol to intestinal hyperemia. Am J Physiol 242:G27-G31

32. McHugh PR, Moran TH, Wirth JB 1982 Postpyloric regulation of gastric emptying in rhesus monkeys. Am J Physiol 243:R408-R415

33. Siegel M, Lebenthal E, Krantz B 1984 Effect of caloric density on gastric emptying in premature infants. J Pediatr 104:118-122

34. Husband J, Husband P Aug 231969 Gastric emptying of water and glucose solutions in the newborn. Lancet 409-411

35. Hinder RA, Kelly KA 1977 Canine gastric emptying of solids and liquids. Am J Physiol 233:E335-E340

36. Johnson L, Lundquist PG, Nordstrom H, Nylander G 1978 Experimental studies on fluid pathophysiology in small intestinal obstruction in the rat. Scand J Gastroenterol 13:373-384

37. Siegel M, Lebenthal E, Topper W, Krantz B, Li PK 1982 Gastric emptying in prematures of isocaloric feedings with differing osmolalities. Pediatr Res 16:141-147

38. Kvietys PR, Pittman RP, Chou CC 1976 Contribution of luminal concentration of nutrients and osmolality to postprandial intestinal hyperemia in dogs. Proc Soc Exp Biol Med 152:659-666

39. Dudgeon DL, Spoon D, Randall P 1981 The effects of gastric hyperosmotic glucose feedings on regional perfusion in the neonatal piglet. J Pediatr Surg 16:854-858

40. Szabo JS, Mayfield SR, Oh W, Stonestreet BS 1985 Effects of hypoxemia on postprandial GI blood flow and oxygen consumption in newborn piglets. Clin Res 32:906A

41. Thompson DG, Richelson E, Malagelada J-R 1982 Perturbation of gastric emptying and duodenal motility through the central nervous system. Gastroenterology 83:1200-1206

42. Bean JW, Sidky MM 1957 Effects of low oxygen on intestinal blood flow, tonus, and motility. Am J Physiol 189:541-547 